\title{
Nota
}

\section{VARIABILIDADE ESPACIAL DA RESISTÊNCIA À PENETRAÇÃO EM NEOSSOLO LITÓLICO DEGRADADO}

\author{
Fabriciano da Cunha Corado Neto(1), Fabricio de Menezes Telo Sampaio( ${ }^{(2)}$, Marcos \\ Emanuel da Costa Veloso(3), Sammy Sidney Rocha Matias ${ }^{(1)^{*}}$, Fabricio Ribeiro Andrade ${ }^{(1)} \mathrm{e}$ \\ Marcio Godofredo Rocha Lobato(1)
}

(1) Universidade Estadual do Piauí, Departamento de Agronomia, Campus Deputado Jesualdo Cavalcanti de Barros, Corrente, Piauí, Brasil.

(2) Universidade Federal do Piauí, Departamento de Solos, Campus Universitário Professora Cinobelina Elvas, Bom Jesus, Piauí, Brasil.

(3) Empresa Brasileira de Pesquisa Agropecuária, Embrapa Meio-Norte, Teresina, Piauí, Brasil.

* Autor correspondente.

E-mail: ymmsa2001@yahoo.com.br

\section{RESUMO}

A resistência à penetração permite avaliar o comportamento do solo diante do manejo adotado. Este estudo teve como objetivo avaliar o comportamento da resistência à penetração nos períodos seco e chuvoso por meio da variabilidade espacial em uma área degradada em Gilbués, PI. O estudo foi conduzido em uma área experimental de 4 ha, pertencente à Embrapa Meio Norte, no período de 2010/2011. O solo da área é um Neossolo Litólico Eutrófico com exposição do horizonte C. Construíram-se um grid irregular e uma transecção próximos à parte central da área, espaçada da seguinte forma: os pontos de número 1 a 21 apresentaram espaçamento de $30 \times 30 \mathrm{~m}$; de 22 a 52 , distanciamento a cada $5 \mathrm{~m}$; de 52 a 53 , com $15 \mathrm{~m}$ de espaçamento; e de 54 a 79 , a cada $30 \mathrm{~m}$, totalizando 79 pontos. Em cada ponto, foi verificada a resistência à penetração e coletadas amostras com estrutura alterada de solo para ser quantificada a umidade do solo, em três profundidades $(0,00-0,10 ; 0,10-0,20$ e $0,20-0,30 \mathrm{~m})$ nos períodos seco e chuvoso. A resistência à penetração do solo evidenciou, em geral, moderada dependência espacial nos períodos seco e chuvoso. A umidade influenciou fortemente os valores de resistência à penetração no período chuvoso.

Palavras-chave: desertificação, geoestatísica, umidade do solo. 


\title{
ABSTRACT: SPATIAL VARIABILITY OF RESISTANCE TO PENETRATION IN AN EUTROPHIC UDORTHENT
}

\begin{abstract}
Resistance to penetration allows evaluation of soil behavior in relation to the management practices adopted. The aim of the present study was to analyze the behavior of resistance to penetration in the dry and rainy season by spatial variability in a degraded area in Gilbués, PI, Brazil. The study was conducted in a 4-ha experimental area, belonging to Embrapa Meio Norte, in 2010/2011. Soil in the area is a Neossolo Litólico Eutrófico (Udorthent) with exposure of the C horizon. We built an irregular grid and a transect near the central part of the area, and undisturbed soil samples were taken from three depths (0.00-0.10, 0.10-0.20, and 0.20-0.30 m) at the following spacing: points numbered from 1-21 have a 30 $\times 30 \mathrm{~m}$ spacing; from 22-52 are spaced every $5 \mathrm{~m}$; 52 and 53 have a $15 \mathrm{~m}$ spacing; and 54-79 are spaced every $30 \mathrm{~m}$, for a total of 79 points. At each point, resistance to penetration was verified, and undisturbed soil samples were collected in order to quantify soil moisture for three depths (0.00-0.10, 0.10-0.20, and 0.20-0.30 m) in the dry and rainy season. In general, soil resistance to penetration showed moderate spatial dependence in the dry and rainy seasons. Moisture strongly influenced the values of penetration resistance in the rainy season.
\end{abstract}

Keywords: desertification, geostatistics, soil moisture.

\section{INTRODUÇÃO}

A degradação do solo tem provocado perdas na ordem de 840 milhões de toneladas por ano no Brasil, sendo o Nordeste responsável por $10 \%$ dessas perdas (Santos et al., 2013). Nessa região, destaca-se o município de Gilbués, PI, com a maior área em processo de desertificação do país, chamando atenção pelo acelerado nível de degradação (Lopes et al., 2011).

As intervenções antrópicas no uso do solo modificam seus atributos físicos, conduzindo a problemas como a compactação do solo, com o aumento da densidade do solo, elevação da resistência à penetração e diminuição da porosidade total (Oliveira et al., 2013). Essas mudanças alteram negativamente a distribuição do diâmetro dos poros, a agregação e o teor de matéria orgânica do solo, interferindo também no processo de troca gasosa do solo. A compactação do solo prejudica o desenvolvimento radicular e a produtividade das culturas (Blainski et al., 2008). Como exemplo, o pinhão-manso tem o comprimento radicular e desenvolvimento da parte aérea prejudicados em solos compactados (Ohland et al., 2014).

A resistência à penetração $(\mathrm{RP})$ tem sido utilizada como indicador da compactação do solo em diversos sistemas de produção por ser um parâmetro de fácil determinação e estar diretamente relacionada com o crescimento das plantas (Bergamin et al., 2010). O teor de água do solo influencia o resultado da RP, existindo uma relação inversa entre esses dois atributos (Mome Filho et al., 2014). Diversos autores afirmaram que valores de RP acima de 2,0 MPa são considerados prejudiciais para o desenvolvimento das raízes (USDA, 1993; Araújo et al., 2004; Blainski et al., 2008; Guimarães et al., 2013).
A variabilidade espacial tem se evidenciado uma ferramenta fundamental na interpretação dos resultados de atributos do solo (Souza et al., 2010a,b). Grego et al. (2012) demostraram que é possível usar mapas de atributos do solo para identificar a degradação, como também recomendar manejos para recuperar as áreas degradadas. Assim, a distribuição espacial dos atributos do solo em áreas que estejam em processo de degradação ou já degradadas proporciona conhecimentos fundamentais para monitorar o comportamento dos seus atributos espacialmente, a fim de compreender os processos erosivos ocorrentes na região do núcleo de desertificação (Lopes et al., 2011; Santos et al., 2013).

O presente trabalho baseou-se na hipótese de que a umidade influencia a variabilidade espacial da resistência à penetração do solo. Assim, objetivou-se avaliar a variabilidade espacial da resistência à penetração em período seco e chuvoso em Neossolo Litólico Eutrófico degradado.

\section{MATERIAL E MÉTODOS}

O estudo foi realizado no município de Gilbués, na região sudeste do Estado do Piauí, nas coordenadas $09^{\circ} 51^{\prime} 18^{\prime \prime}$ de latitude sul e $45^{\circ} 22$ ' $05^{\prime}$ 'de longitude oeste. O clima da região é do tipo Aw, megatérmico de acordo com a classificação de Köppen, com moderada deficiência hídrica no inverno, temperatura média de $26,5^{\circ} \mathrm{C}$, precipitação pluvial anual de $1.200 \mathrm{~mm}$, com estação chuvosa nos meses de outubro a abril, sendo o trimestre mais chuvoso concentrado entre janeiro e março, e altitude de $481 \mathrm{~m}$.

Utilizou-se uma área de aproximadamente 4 ha, tendo no seu entorno inúmeras voçorocas. O solo foi classificado como Neossolo Litólico 
Eutrófico, com exposição do horizonte C, textura franco-argilossiltoso. A cobertura do solo da área apresentava diferentes composições com cerca de 1 ha cada: pinhão-manso consorciado com a gramínea conhecida como "rabo de raposa" (Andropogon leocostacyus) - $\mathrm{C} 1$; pinhão-manso consorciado com Brachiaria decumbens - C2; pinhão-manso consorciado com Brachiaria brizantha cultivar Piatã - C3; e pinhão-manso consorciado com capim Andropógon - $\mathrm{C} 4$.

Construíram-se um grid e uma transecção próximos à parte central da área, com 79 pontos, locais onde foram realizadas as amostragens. Para melhor observação da variabilidade dos dados, obedeceram-se aos seguintes critérios: os pontos de número 1 a 21 apresentaram espaçamento de $30 \times 30 \mathrm{~m}$; de 22 a 52 , distanciamento a cada $5 \mathrm{~m}$; de 52 a 53 , com 15 m de espaçamento; e de 54 a 79, a cada $30 \mathrm{~m}$, conforme apresentado na figura $1 . \mathrm{Em}$ cada ponto, realizaram-se o teste de penetrometria e a retirada de amostras com estrutura alterada para determinar a umidade do solo nas profundidades de 0,00-0,10; 0,10-0,20; e 0,20-0,30 m. A distribuição da cobertura do solo na área se apresentou da seguinte forma: C1, entre os pontos 01 e 16 do grid de amostragem; C2, entre os pontos 17 e 52; C3, entre os pontos 53 e 68; e C4, entre os pontos 69 e 79 .

Os ensaios foram desenvolvidos em dois períodos: seco (setembro de 2011) e chuvoso (novembro de 2011). Para determinar a RP, utilizou-se um penetrômetro de impacto com haste de $0,40 \mathrm{~m}$. A umidade do solo foi obtida por meio de amostras retiradas em trincheiras de $0,30 \mathrm{~m}$ de profundidade, e analisadas no laboratório de solos da Universidade Federal do Piauí, em Bom Jesus, PI. O material foi pesado e levado para uma estufa a $105^{\circ} \mathrm{C}$ e deixado para secar por um período de $24 \mathrm{~h}$ para quantificar a umidade em cada ponto.

Utilizou-se inicialmente a estatística descritiva, com a finalidade de caracterizar as tendências de posições centrais e de dispersão dos dados, além de expressar a sua distribuição. Foram estimadas as seguintes medidas: de posição (média, mediana, máximo e mínimo), de dispersão (desvio-padrão e coeficiente de variação) e a forma da dispersão (simetria e curtose). Para a análise do coeficiente de variação (CV), usou-se a classificação de Warrick e Nielsen (1980), com variabilidade baixa para valores menores de $12 \%$, média entre 12 e $60 \%$ e alta para valores maiores de $60 \%$.

Para determinar a variabilidade espacial, considerou-se a teoria das variáveis regionalizadas, que dispõe de diferentes métodos de análise de variação espacial, sendo uma delas o semivariograma (Vieira, 2000). Os semivariogramas de cada atributo foram obtidos mediante o software GS+ (Robertson, 2008). Foram ajustados aos dados os modelos esférico (Esf), exponencial (Exp) e gaussiano (Gau).

Por meio desses modelos, realizou-se a predição de cada atributo em zonas não amostradas mediante

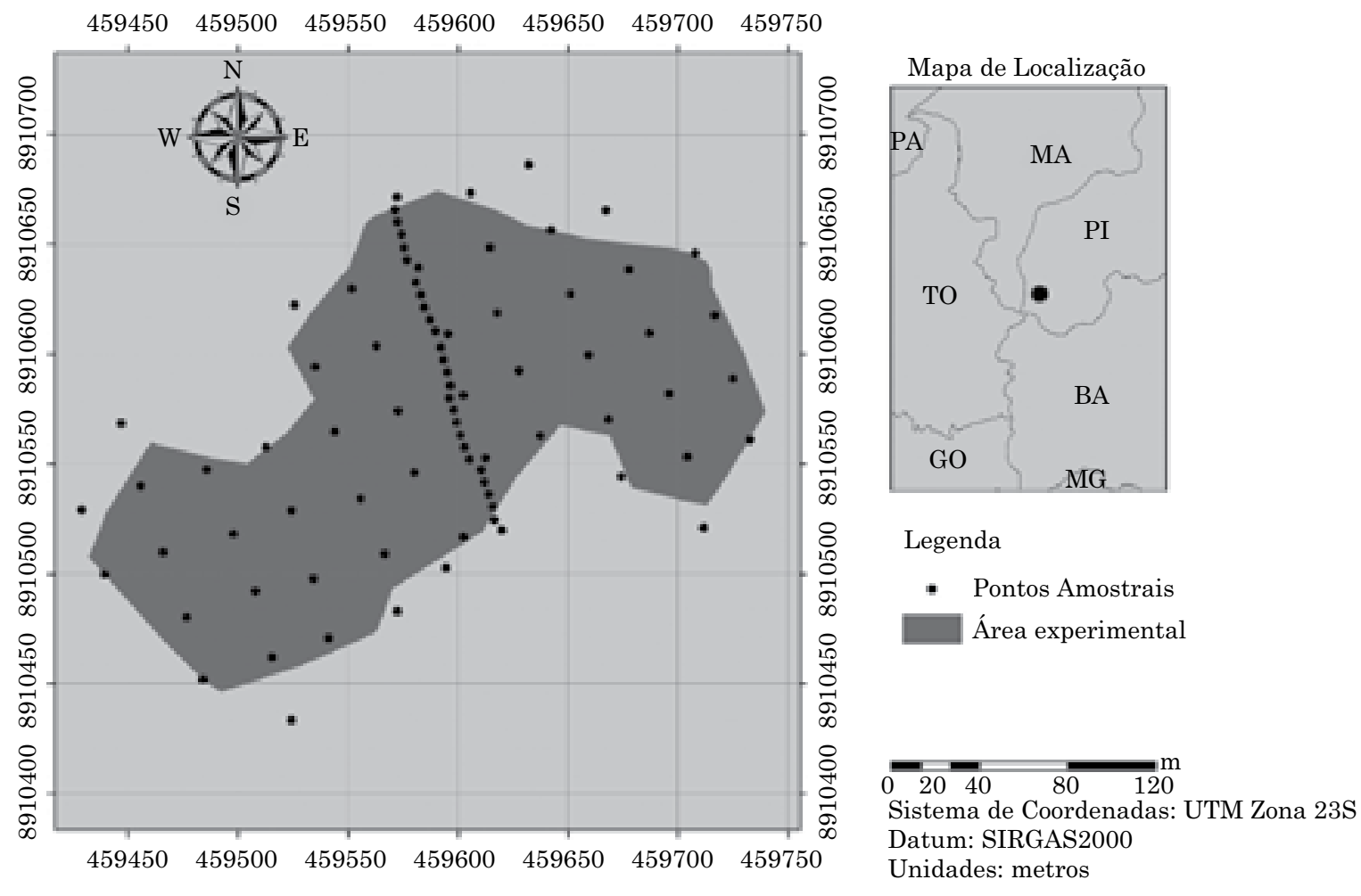

Figura 1. Distribuição da malha amostral e localização do município de Gilbués, PI. 
krigagem, representados em mapas de contorno, utilizando o software Surfer 8.00. A escolha dos modelos teóricos foi realizada, observando-se a soma do quadrado dos resíduos (SQR), o coeficiente de determinação $\left(R^{2}\right)$ e, posteriormente, o coeficiente de correlação obtido pela técnica da validação cruzada.

A classificação do grau da dependência espacial (GDE) foi feita com base na razão entre o efeito pepita e o patamar $\left(\mathrm{C}_{0} / \mathrm{C}_{0}+\mathrm{C}_{1}\right)$, sendo considerada forte para GDE superior de $75 \%$, moderada para GDE entre 25 e $75 \%$ e fraca para GDE inferior a $25 \%$ (Cambardella et al., 1994).

\section{RESULTADOS E DISCUSSÃO}

Todas as variáveis analisadas em ambas as profundidades apresentaram valores de assimetria positivos, com mediana menor que a média, com exceção da umidade na época chuvosa (Quadro 1).

A média da resistência à penetração nas duas situações apresentadas em relação às umidades do solo foi alta em todas as profundidades no período seco, com valores acima de 2,0 MPa, considerada prejudicial às plantas (Guimarães et al., 2013). No período chuvoso, esses valores permaneceram altos, excetuando-se na profundidade de 0,00-0,10 m, que foi de 1,32 MPa. Freitas et al. (2012), estudando a RP de um Neossolo Quartzarênico sob pastagem, verificaram durante um período seco e um chuvoso, valores de RP de 3,40 e 1,69, respectivamente, na camada de 0,10-0,20 m, evidenciando o efeito da umidade do solo sob esse parâmetro. Em dois solos (Latossolo Vermelho Eutroférrico e Latossolo Vermelho Distroférrico) sob 30 anos de cultivo de cana-de-açúcar. Souza et al. (2010a) verificaram diferenças nos valores de RP, evidenciando dessa forma que tal parâmetro pode ser variável de acordo com o manejo, o tipo de solo e a época de amostragem.
A média dos valores encontrados entre o período seco e úmido foi alterada apenas para a camada mais superficial $(0,00-0,10 \mathrm{~m})$. Esse aspecto pode ser justificado pelo fato das análises terem sido executadas no início do período chuvoso; e a alteração causada pela umidade provavelmente ocorreu na camada mais superficial.

Os coeficientes de variação (CV) da RP em ambas as profundidades e os períodos (seco e chuvoso) são considerados médios para variáveis de solo de acordo com a classificação proposta por Warrick e Nielsen (1980). O CV da RP no solo seco diminuiu com o aumento da profundidade. No solo úmido ocorreu o inverso, ou seja, à medida que aumentou a profundidade, o CV também se elevou. Esse efeito pode ser justificado pela homogeneidade dos dados na camada superior no período mais chuvoso, pois a umidade torna-se menos dependente espacialmente, conforme relatado por Sampaio et al. (2010).

Como a quantidade de água existente no solo influencia os valores de resistência do solo à penetração, qualquer alteração na umidade modifica tais valores (Matias et al., 2009; Bottega et al., 2011). Mion et al. (2012) encontraram valores de CV para a RP de 48 , 58 e 63 nas profundidades de 0,00-0,10;0,100,20 e 0,20-0,30 m, respectivamente, em um Argissolo Amarelo sob pastagem. Sampaio et al. (2010), quantificando a umidade de um Latossolo Vermelho-Amarelo sob plantio direto, encontraram valores de CV situados dentro do intervalo de 10 a $20 \%$.

Os valores de assimetria positiva demonstram haver tendência de concentração dos valores abaixo da média observada, sendo tal tendência tanto mais expressiva quanto maior for o valor obtido; situação inversa se dá para valores negativos desse coeficiente. Com exceção da umidade no período chuvoso que apresentou distribuição de frequência platicúrtica, ou seja, curtose negativa,

Quadro 1. Parâmetros da estatística descritiva para resistência do solo à penetração e umidade do solo nas profundidades de $0,00-0,10 ; 0,10-0,20$ e $0,20-0,30 \mathrm{~m}$, em período seco e chuvoso

\begin{tabular}{|c|c|c|c|c|c|c|c|c|c|}
\hline Período & Profundidade & Média & Mediana & $\mathrm{CV}$ & Desvio-padrão & Máximo & Mínimo & AS & $\mathbf{K}$ \\
\hline & $\mathrm{m}$ & & & $\%$ & & & & & \\
\hline & & \multicolumn{8}{|c|}{ Resistência à penetração (MPa) } \\
\hline \multirow[t]{3}{*}{ Seco } & $0,00-0,10$ & 2,51 & 2,22 & 49,0 & 1,23 & 6,58 & 0,75 & 1,41 & 2,56 \\
\hline & $0,10-0,20$ & 2,32 & 2,05 & 45,7 & 1,06 & 5,93 & 0,82 & 1,42 & 2,39 \\
\hline & $0,20-0,30$ & 3,46 & 3,17 & 42,8 & 1,48 & 7,31 & 1,11 & 0,58 & $-0,30$ \\
\hline \multirow[t]{4}{*}{ Chuvoso } & $0,00-0,10$ & 1,32 & 1,28 & 29,5 & 0,39 & 3,11 & 0,80 & 2,13 & 6,61 \\
\hline & $0,10-0,20$ & 2,20 & 1,92 & 50,9 & 1,12 & 6,00 & 0,82 & 1,30 & 1,59 \\
\hline & $0,20-0,30$ & 3,55 & 3,42 & 53,2 & 1,89 & 11,06 & 0,79 & 0,98 & 1,92 \\
\hline & & \multicolumn{8}{|c|}{ Umidade do solo (\%) } \\
\hline Seco & & 4,45 & 4,28 & 38,7 & 1,72 & 10,46 & 1,03 & 0,49 & 0,85 \\
\hline Chuvoso & & 16,29 & 16,34 & 15,7 & 2,56 & 22,22 & 9,29 & $-0,34$ & 0,36 \\
\hline
\end{tabular}

CV: coeficiente de variação; AS: assimetria; K: curtose. 
os demais parâmetros tiveram distribuição de frequência leptocúrtica, evidenciando, assim, que a maioria dos atributos do solo possui os dados próximos ao seu centro no gráfico de distribuição de frequência.

Embora os coeficientes de assimetria e curtose demonstrem que os atributos do solo têm distribuições assimétricas, os valores da média e mediana das variáveis estudadas se evidenciaram similares, indicando que os conjuntos de dados não apresentam assimetria acentuada e também possuem ou se aproximam da distribuição normal. Isso pode indicar que as medidas de tendência central não são dominadas por valores atípicos na distribuição (Cambardella et al., 1994).

$\mathrm{O}$ modelo que melhor se ajustou à distribuição espacial dos valores de resistência à penetração em ambos os períodos foram os modelos exponencial e esférico (Figura 2) com $\mathrm{R}^{2}$ variando de 0,51 a 0,97, com exceção na profundidade de 0,00-0,10 m no período seco, onde o melhor ajuste foi obtido utilizando o modelo gaussiano $\left(\mathrm{R}^{2}=0,67\right)$ (Figura 2). Para os dados de umidade do solo em ambos os períodos, o modelo esférico foi o que melhor se ajustou aos dados, com $R^{2}$ de 0,92 e 0,88 nas épocas seca e chuvosa, respectivamente (Figura 2, Quadro 2). Os modelos esférico e exponencial que se ajustaram aos dados deste estudo corroboraram os resultados de pesquisas que indicam esses modelos como os de maior ocorrência para atributos do solo (Cruz et al., 2010; Campos et al., 2012). Adicionalmente, Mion et al. (2012), estudando a variabilidade espacial dos atributos físicos do solo em um Argissolo Amarelo de textura arenosa cultivado com pastagens, não encontraram ajuste a nenhum modelo teórico aos semivariogramas experimentais para a RP e umidade gravimétrica na camada de 0,00-0,10 m e umidade gravimétrica na camada de 0,20-0,30 m.

Os valores de efeito pepita $\left(\mathrm{C}_{0}\right)$ para a $\mathrm{RP}$ cresceram de acordo com a profundidade de amostragem em ambos os períodos de amostragem, sendo o maior valor encontrado no período seco na profundidade de 0,20-0,30 m (Quadro 2). Da mesma forma, o maior valor do efeito pepita para a umidade foi no período seco. Esses resultados sugerem que a distância de amostragem preconizada neste estudo foi suficiente para indicar e identificar a variabilidade dos atributos químicos do solo (Cambardella et al., 1994).

Em relação ao patamar $\left(\mathrm{C}_{0}+\mathrm{C}_{1}\right)$, observouse que os dados de RP seguiram comportamento semelhante ao observados para o efeito pepita $\left(\mathrm{C}_{0}\right)$, em que, de acordo com o aumento da profundidade, há a elevação do patamar. No entanto, o maior valor foi encontrado na camada de $0,20-0,30 \mathrm{~m}$ no período chuvoso (Quadro 2). Para a umidade do solo, o maior valor foi obtido no período chuvoso, demonstrando que entre esses valores a estacionariedade é real e contribui para definir a variabilidade espacial dos pontos amostrados. Os modelos ajustados aos dados dos atributos físicos são considerados transitivos por possuir patamar, ou seja, a partir de determinado valor da distância entre amostras não existe mais dependência espacial (Siqueira et al., 2010).

A relação entre o efeito pepita $\left(\mathrm{C}_{0}\right)$ e o patamar $\left(\mathrm{C}_{0}+\mathrm{C}_{1}\right)$ do semivariograma indica o grau de dependência espacial dos atributos (Campos et al., 2012; Dalchiavon et al., 2011, Neves Neto et al., 2013). Neste estudo, a relação $\mathrm{C}_{0} /\left(\mathrm{C}_{0}+\mathrm{C}_{1}\right)$ evidenciou moderada dependência para a maioria dos atributos, com exceção da $\mathrm{RP}$ (0,00-0,10 e 0,20-0,30 m) e umidade no período chuvoso (Quadro 2), que obtiveram forte grau de dependência espacial, segundo a classificação de Cambardella et al. (1994). Dessa forma, pode-se observar que a distribuição dos atributos no espaço não é aleatória, uma vez que todos apresentaram valores moderados ou fortes para o grau de dependência espacial. Coelho et al. (2012) encontraram forte dependência espacial da RP nas camadas de 0,00-0,10;0,10-0,20 e 0,20-0,30 $\mathrm{m}$, ao avaliarem a variabilidade dos atributos físicos de solo cultivado com manga. Em Cambissolo Háplico Alítico cultivado com mandioca, nas camadas de 0,00-0,15 e 0,15-0,30 m, Campos et al. (2012), ao avaliarem a umidade do solo, observaram fraca e moderada dependência espacial nas respectivas camadas.

Os valores de alcance (A) demonstram até que ponto as amostras são correlacionadas entre si, representando, dessa maneira, a distância máxima de dependência espacial entre amostras (Vieira, 2000). Os valores do alcance da RP no período seco variaram de 45,90 a 79,84 m e, no período chuvoso, de 34,80 a 108,60 m (Quadro 2). Para a umidade, nos períodos seco e chuvoso, os alcances obtidos foram de 116,50 e 104,60 m, respectivamente (Quadro 2). Alcance de $41,6 \mathrm{~m}$, para a $\mathrm{RP}$ na profundidade de $0,00-0,05 \mathrm{~m}$, e de $58,8 \mathrm{~m}$, na profundidade de 0,15-0,20 m, foi encontrado por Souza et al. (2001) ao analisarem a variabilidade espacial de atributos físicos de um Latossolo Vermelho Distrófico sob semeadura direta em Selvíria, MS.

O alcance da dependência espacial é um parâmetro geoestatístico importante na agricultura por auxiliar o delineamento de futuras amostragens de solo, indicando a máxima distância entre amostras para determinar atributos do solo com boa representatividade (Sampaio et al., 2010). Isso implica que os dados apresentados podem colaborar em futuras amostragens com finalidade de monitorar as transformações ambientais ocorrentes na região, principalmente aqueles compreendidos dentro dos processos erosivos ocorrentes do núcleo de desertificação. 
Seco

0,00-0,10 m

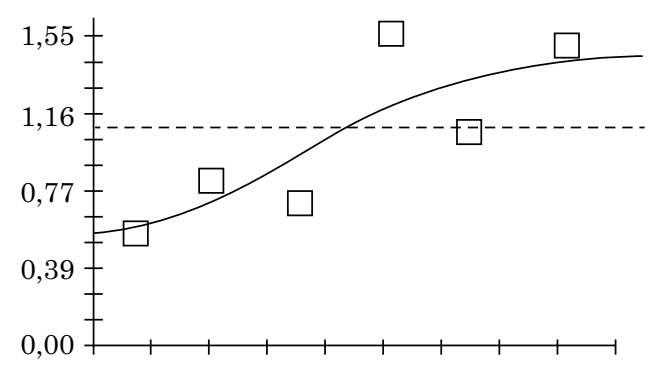

0,10-0,20 m

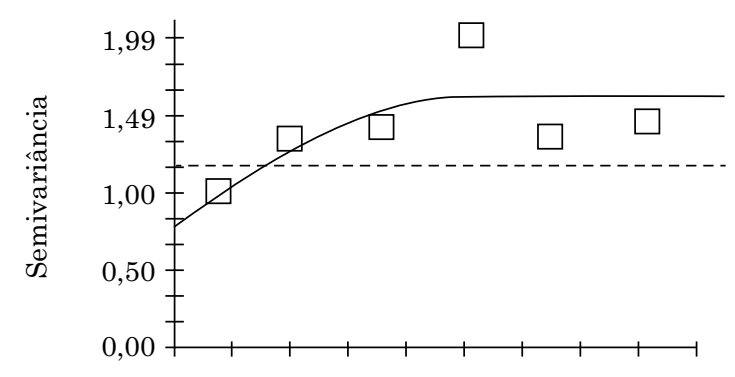

0,20-0,30 m

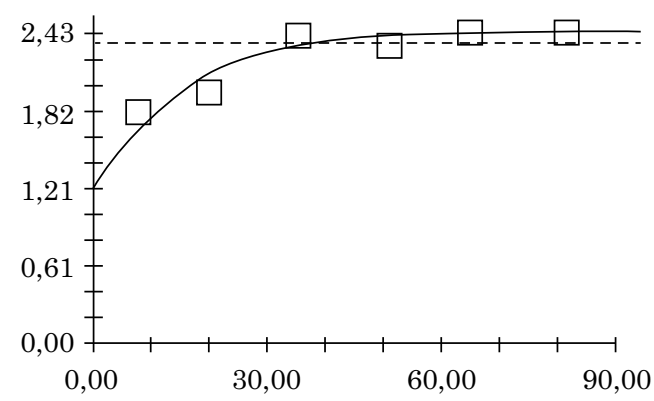

Período

Chuvoso

0,00-0,10 m

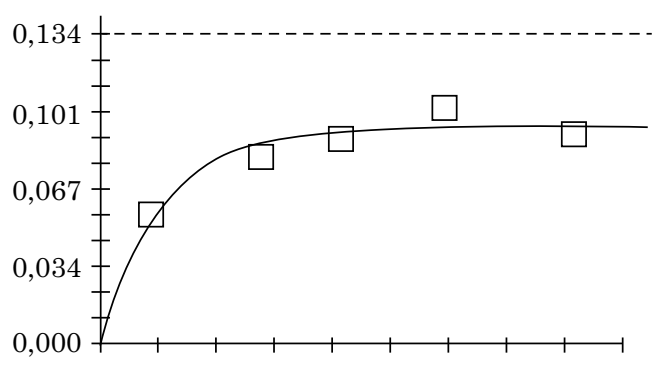

0,10-0,20 m

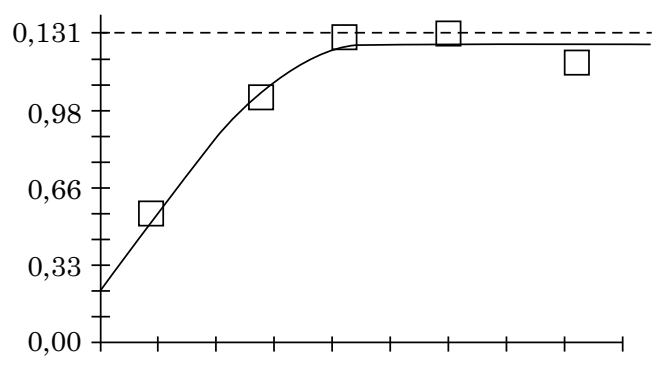

0,20-0,30 m

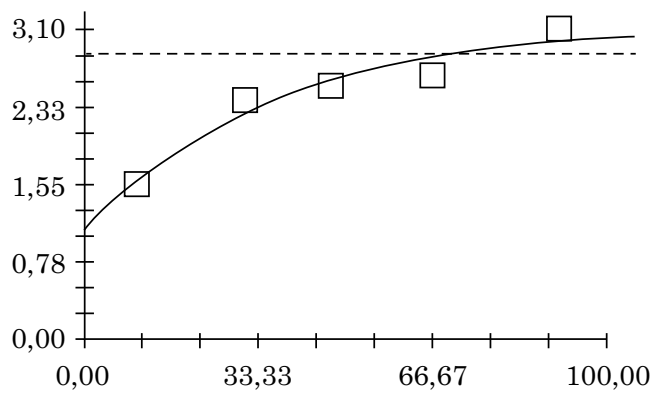

Distância (m)

Figura 2. Semivariogramas com modelos ajustados aos dados da resistência à penetração (RP) nas três profundidades analisadas $(0,00-0,10 ; 0,10-0,20$ e 0,20-0,30 m) nos períodos seco e chuvoso.

Quadro 2. Análise geoestatística para resistência à penetração $(\mathrm{RP})$ e umidade do solo nas profundidades de 0,00-0,10; 0,10-0,20 e 0,20-0,30 m, em período seco e chuvoso

\begin{tabular}{lccccccc}
\hline Atributo/Período & Profundidade & Modelo & $\mathbf{C}_{\mathbf{0}}$ & $\mathbf{C}_{\mathbf{0}}+\mathbf{C}_{\mathbf{1}}$ & $\mathbf{A}$ & $\mathbf{G D E}^{\mathbf{2}}$ \\
\hline \multirow{2}{*}{$\mathrm{mP} /$ Seco } & $\mathrm{m}$ & & & $\mathrm{m}$ & $\%$ & \multicolumn{1}{c}{$\mathbf{R}^{\mathbf{2}}$} \\
& $0,00-0,10$ & Gaussiano & 0,568 & 1,454 & 79,84 & 39,06 & 0,67 \\
& $0,10-0,20$ & Esférico & 0,801 & 1,603 & 49,90 & 49,96 & 0,51 \\
& $0,20-0,30$ & Exponencial & 1,214 & 2,429 & 45,60 & 49,97 & 0,88 \\
Umidade/Seco & & Esférico & 1,418 & 2,969 & 116,50 & 33,32 & 0,92 \\
RP/Chuvoso & $0,00-0,10$ & Exponencial & 0,0001 & 0,094 & 34,80 & 0,10 & 0,88 \\
& $0,10-0,20$ & Esférico & 0,224 & 1,255 & 49,70 & 17,84 & 0,97 \\
Umidade/Chuvoso & $0,20-0,30$ & Exponencial & 1,120 & 3,152 & 108,60 & 35,53 & 0,95 \\
\hline
\end{tabular}

$\mathrm{C}_{0}$ : Efeito pepita; $\mathrm{C}_{0}+\mathrm{C}_{1}$ : patamar; A: alcance; GDE: grau de dependência espacial; e $\mathrm{R}^{2}$ : coeficiente de determinação do modelo. 
Houve aumento dos valores do alcance para $\mathrm{RP}$ à medida que se aprofundou no perfil do solo em ambos os períodos de avaliação, o que implica dizer que quanto maior a profundidade, mais homogênea será a RP. Isso deve ocorrer porque as camadas subsuperficiais sofrem menor interferência antrópica (Bertol et al., 2001), se tornando mais homogêneas.

Para visualizar a distribuição dos valores de RP e umidade nos pontos amostrados, realizou-se a krigagem dos dados, gerando mapas de superfície (a)

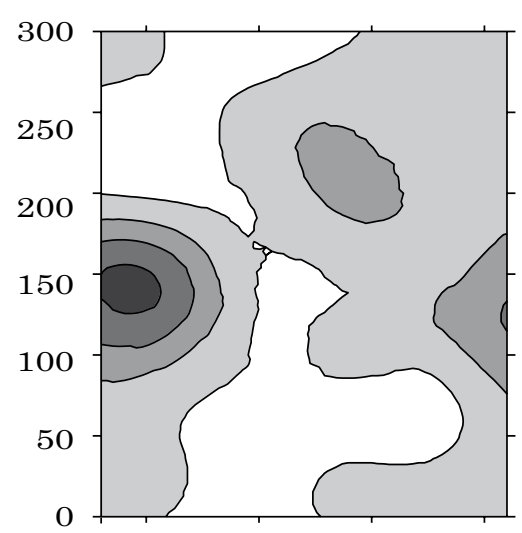

(b)

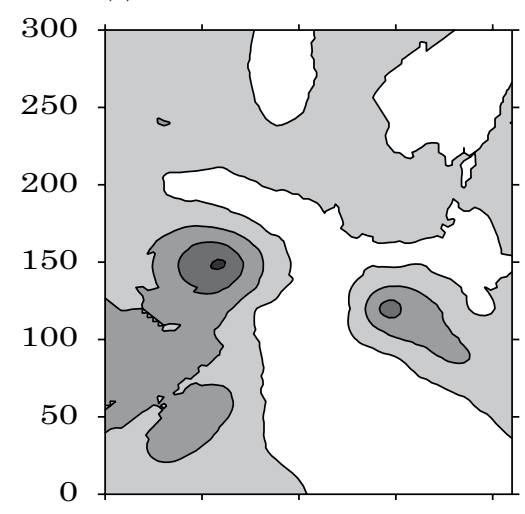

(c)

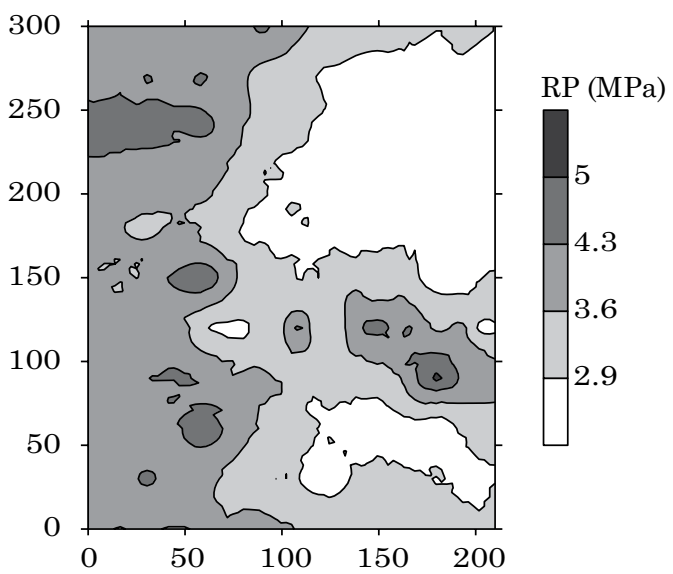

$\mathrm{RP}(\mathrm{MPa})$

4.8

3.9

$-3$

2.1

$\mathrm{RP}(\mathrm{MPa})$

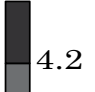

$-3.5$

$-2.8$

$-2.1$ (a)

Chuvoso

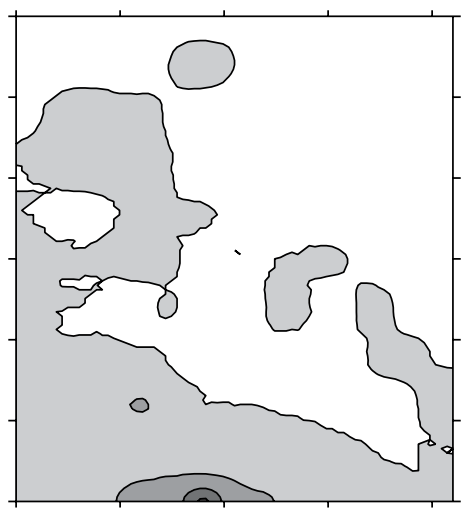

$\mathrm{RP}(\mathrm{MPa})$

(b)

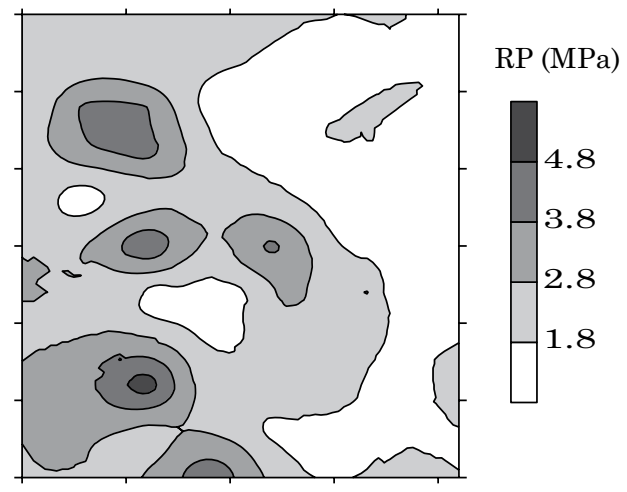

(c)

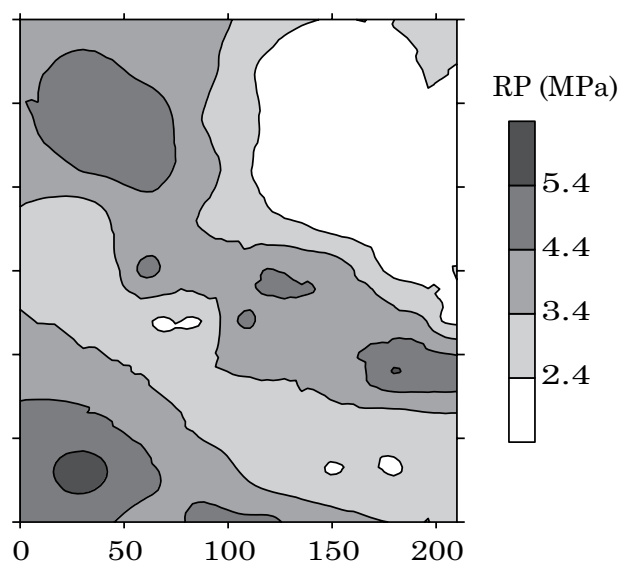

Figura 3. Mapas da distribuição da resistência do solo à penetração (RP) nas profundidades de 0,00-0,10 m (a); 0,10-0,20 m (b) e 0,20-0,30 m (c), nos períodos seco e chuvoso, em área de Neossolo Litólico Eutrófico. 

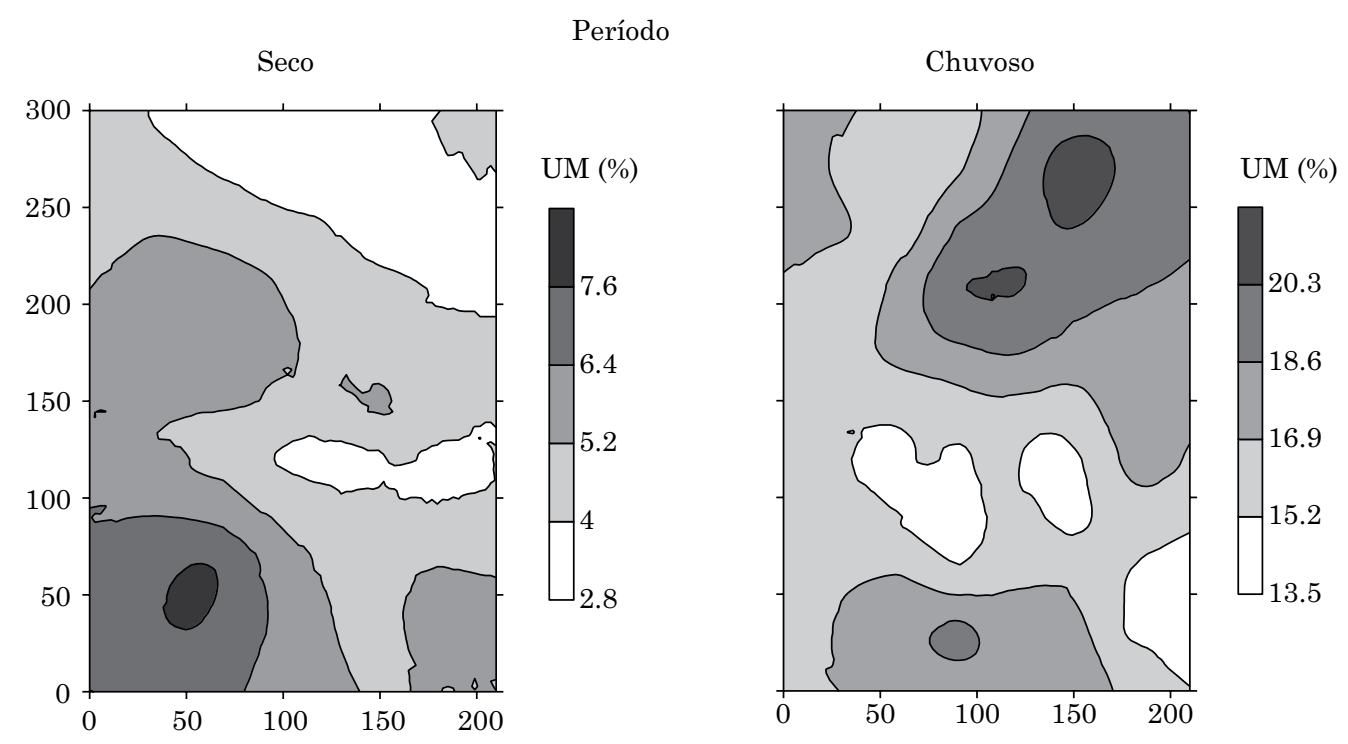

Figura 4. Mapas da umidade do solo (UM) nos períodos seco e chuvoso, em área de Neossolo Litólico Eutrófico.

(Figuras 3 e 4). Esses mapas facilitam a visualização da distribuição espacial das variáveis e auxiliam no planejamento do manejo da área (Sampaio et al., 2010). Na figura 3, estão representadas as resistências à penetração nas diferentes profundidades para os períodos seco e chuvoso.

Os mapas de krigagem ajudam a identificar zonas propensas à erosão em razão da maior compactação e, com isso, possibilita a tomada de decisões quanto ao manejo a fim de reduzir e, ou, eliminar zonas propensas a degradação ambiental. Detectaram-se zonas compactadas, com predominância de valores acima de $2 \mathrm{MPa}$, principalmente na parte oeste da área. Uma provável explicação para esse efeito pode ser por causa do maior grau de degradação da pastagem nessa área em razão da menor cobertura vegetal e do pisoteio pelos animais.

A umidade do solo no período chuvoso foi duas a três vezes maior que no período seco, o que se reflete significativamente na RP (Figura 4). Verificou-se grande relação entre os mapas de umidade e RP no período chuvoso. No período seco, os baixos valores de umidade e a baixa variabilidade dos dados na área podem explicar a fraca relação dos dois atributos estudados nesse período.

\section{CONCLUSÕES}

A resistência à penetração do solo evidenciou, em geral, moderada dependência espacial nos períodos seco e chuvoso.

A umidade influenciou fortemente os valores de resistência à penetração no período chuvoso.

\section{AGRADECIMENTOS}

À Empresa Brasileira de Pesquisa Agropecuária - Embrapa Meio Norte, e à Fundação de Amparo à Pesquisa do Estado do Piauí - FAPEPI.

\section{REFERÊNCIAS}

Araújo MA, Tormena CA, Silva AP. Propriedades físicas de um Latossolo Vermelho distrófico cultivado e sob mata nativa. R Bras Ci Solo. 2004;28:337-45.

Bergamin AC, Vitorino ACT, Franchini JC, Souza CMA, Souza FR. Compactação em um Latossolo Vermelho distroférrico e suas relações com o crescimento radicular do milho. R Bras Ci Solo. 2010;34:681-91.

Bertol I, Beutler JF, Leite D, Batistela O. Propriedades físicas de um cambissolo húmico afetadas pelo tipo de manejo do solo. Sci Agric. 2001;58:555-60.

Blainski E, Tormena CA, Fidalski J,Guimarães RAL. Quantificação da degradação física do solo por meio da curva de resistência do solo à penetração. R Bras Ci Solo. 2008;32:975-83.

Bottega EL, Bottega SP, Silva SA, Queiroz DM, Souza CMA, Rafull LZL. Variabilidade espacial da resistência do solo à penetração em um Latossolo Vermelho distroférrico. R Bras Ci Agron. 2011;6:331-6.

Cambardella CA, Moorman TB, Parkin TB, Karlen DL, Turco RF, Konopka AE. Field-scale variability of soil properties in Central Iowa. Soil Sci Soc Am J. 1994;58:1501-11.

Campos MCC, Oliveira IA, Santos LAC, Aquino RE, Soares MRD. Variabilidade espacial da resistência do solo à penetração e umidade em áreas cultivadas com mandioca na região de Humaitá, AM. R Agro@mb Online. 2012;6:9-16. 
Coelho DS, Cortez JW, Olszevski N. Variabilidade espacial da resistência mecânica à penetração em Vertissolo cultivado com manga no perímetro irrigado de Mandacaru, Juazeiro, Bahia, Brasil. R Bras Ci Solo. 2012;36:755-63.

Cruz JS, Assis Junior RN, Matias SSR, Camacho-Tamayo JH, Tavares RC. Análise espacial de atributos físicos e carbono orgânico em Argissolo Vermelho-Amarelo cultivado com cana-de-açúcar. Ci Agrotec. 2010;34:271-8.

Dalchiavon FC, Carvalho MP, Nogueira DC, Romano D, Abrantes FL, Assis JT, Oliveira MS. Produtividade da soja e resistência mecânica à penetração do solo sob sistema plantio direto no cerrado brasileiro. Pesq Agropec Trop. 2011;41:8-19.

Freitas IC, Santos FCV, Custodio Filho RO, Silva NRA, Correchel V. Resistência à penetração em Neossolo Quartzarênico submetido a diferentes formas de manejo. R Bras Eng Agríc Amb. 2012;16:1275-81.

Grego CR, Rodrigues CAG, Nogueira SF, Gimenes FMA, Oliveira A, Almeida CGF, Furtado ALS, Dermachi JJAA. Variabilidade espacial do solo e da biomassa epígea de pastagem, identificada por meio de geostatística. Pesq Agropec Bras. 2012;47:1404-12.

Guimarães RML, Tormena CA, Blainski E, Fidalski J. Intervalo hídrico ótimo para avaliação da degradação física do solo. R Bras Ci Solo. 2013;37:1512-21.

Lopes LSO, Santos RWP, Miguel Filho MA. Núcleo de desertificação de Gilbués (PI): causas e intervenções. R Geogr. 2011;20:53-66.

Matias SSR, Barbosa JA, Ticelli M, Panosso AR, Camara FT. Atributos físicos de um Latossolo Vermelho submetido a diferentes usos. R Ci Agron. 2009;40:331-8.

Mome Filho EA, Silva AP, Figueiredo GC, Gimenes FHS,Vitti AC. Compared performance of penetrometers and effect of soil water content on penetration resistance measurements. $\mathrm{R}$ Bras Ci Solo. 2014;38:744-54

Mion RL, Nascimento EMS, Sales FAL, Silva SF, Duarte JML, Sousa BM. Variabilidade espacial da porosidade total, umidade e resistência do solo à penetração de um Argissolo Amarelo. Semina: Ci. Agron. 2012;33:2057-66.

Neves Neto DN, Santos AC, Santos PM, Melo JC, Santos JS. Análise espacial de atributos do solo e cobertura vegetal em diferentes condições de pastagem. R Bras Eng Agríc Amb. 2013;17:995-1004.

Oliveira IA, Campos MCC, Soares MDR, Aquino RE, Marques Junior J, Nascimento EP. Variabilidade espacial de atributos físicos em um Cambissolo Háplico, sob diferentes usos na região sul do Amazonas. R Bras Ci Solo. 2013;37:1103-12.

Ohland T, Lana MC, Frandoloso JF, Rampim L, Bergmann JR, Cabreira DT. Influência da densidade do solo no desenvolvimento inicial do pinhão-manso cultivado em Latossolo Vermelho eutroférrico. R Ceres. 2014;61:622-30.

Robertson GP. GS+: Geostatistics for the environmental sciences. Plainwell [USA]: Gamma Design Software; 2008

Sampaio FMT, Ferreira MM, Oliveira MS, Almeida AC, José MR. Variabilidade espacial da umidade de um Latossolo Vermelho-Amarelo sob plantio direto. Eng Agríc. 2010;30:854-61.

Santos HL, Marques Junior J, Matias SSR, Siqueira DS, Martins Filho MV. Erosion factors and magnetic susceptibility in different compartments of a slope in Gilbués - PI, Brazil. Eng Agríc. 2013;33:64-74.

Siqueira DS, Marques Júnior J, Pereira GT. The use of landforms to predict the variability of soil and orange attributes. Geoderma. 2010;155:55-66.

Souza ZM, Silva MLS, Guimarães GL, Campos DTS, Carvalho MP, Pereira GT. Variabilidade espacial de atributos físicos em um Latossolo Vermelho Distróferrico sob semeadura direta em Selvíria (MS). R Bras Ci Solo. 2001;25:699-707.

Souza ZM, Marques Júnior J, Pereira GT. Geoestatística e atributos do solo em áreas cultivadas com cana-de-açúcar. Ci Rural. 2010a;40:48-56.

Souza ZM, Cerri DGP, Magalhães PSG, Siqueira DS. Spatial variability of soil attributes and sugarcane yield in relation to topographic location. R Bras Eng Agríc Amb. 2010b;14:1250-6.

United States Department of Agriculture - USDA. Soil survey manual. Soil Survey Division Staff. Washington, DC: 1993.

Vieira SR. Geoestatística em estudo da variabilidade espacial do solo. Tópicos Ci Solo. 2000;1:1-54.

Warrick AW, Nielsen DR. Spatial variability of soil physical properties in the field. In: Hillel D, editor. Applications of soil physics. New York: Academic Press; 1980. p.319-44. 